\title{
How do Australian patients rate their general practitioner? A descriptive study using the General Practice Assessment Questionnaire
}

\author{
Maria Potiriadis, Patty Chondros, Gail Gilchrist, Kelsey Hegarty, Grant Blashki and Jane M Gunn
}

W ith the emergence of a strong health consumer movement $t^{1,2}$ and an emphasis on quality improvement programs around the world, ${ }^{3}$ the patient's perspective on the quality of health care has become a central driver of health care reform. In developed countries, patients are increasingly seen as well placed to make judgements about health care services. ${ }^{4}$ As a consequence, surveying patients about their experience of care is becoming a routine part of assessing the quality of hospital care and primary health care. ${ }^{5-9}$

Greater patient satisfaction with health care is associated with improved compliance, continuity of care and clinical outcomes. ${ }^{10}$ The General Practice Assessment Questionnaire (GPAQ), designed for use in general practice, assesses patient satisfaction with aspects of care. Although it has been extensively used and validated in studies in the United Kingdom, ${ }^{11-14}$ it has not been used on a large sample of general practice patients in Australia.

As part of a large longitudinal study called the Diagnosis, Management and Outcomes of Depression in Primary Care (diamond) study ${ }^{15}$ we included the GPAQ in a mail-out screening survey of patients attending general practices in Victoria. To our knowledge, ours is the first Australian study to report patient satisfaction using the GPAQ.

The GPAQ was chosen because it is brief, was developed in a health system similar to that of Australia, has been shown to be acceptable to a broad cross-section of patients, and has high reliability and validity. ${ }^{13}$ We report patient responses to the GPAQ and explore patient characteristics associated with satisfaction on the six GPAQ scales.

\section{METHODS}

To identify patients eligible for the diamond longitudinal study, 17780 patients from 30 general practices in Victoria were sent a screening survey. A full description of the methods and sample size calculations are detailed elsewhere. ${ }^{15}$ Our article is based on the responses of patients who completed the screening survey. We did not conduct a

\section{ABSTRACT}

Objective: To report patient responses to the General Practice Assessment Questionnaire (GPAQ) as a measure of satisfaction with health care received from Australian general practitioners.

Design, setting and participants: A clustered cross-sectional study involving general practice patients from 30 randomly selected general practices in Victoria. Between January and December 2005, a screening survey, including a postal version of the GPAQ, was mailed to 17780 eligible patients.

Main outcome measure: Scores on the six GPAQ items.

Results: We analysed data from 7130 patients who completed the screening survey and fulfilled our eligibility criteria. Levels of patient satisfaction with general practice care were generally high: mean GPAQ scores ranged from $68.6(95 \% \mathrm{Cl}, 66.1-71.0)$ for satisfaction with access to the practice to $84.0(95 \% \mathrm{Cl}, 82.2-85.4)$ for satisfaction with communication. Intracluster correlations for the GPAQ items ranged from 0.016 for overall satisfaction with the practice to 0.163 for satisfaction with access to the practice. Compared with national benchmarks in the United Kingdom, the GPs and practices participating in our study were rated higher on all six GPAQ items. Multivariable mixed effects linear regression showed that patients who were older, rated their health more highly, visited their GP more frequently and saw the same GP each time tended to express greater satisfaction with their care.

Conclusion: Generally patients reported high levels of satisfaction with GP care. Greater satisfaction with care was associated with older patients, good health, more frequent contact with the GP, and seeing the one GP consistently.

MJA 2008; 189: 215-219

power calculation for this article, as we provide $95 \%$ confidence intervals to summarise the precision of the estimates.

\section{General practitioner recruitment}

Thirty GPs were recruited from a randomly selected list of 200 GPs provided by the Health Insurance Commission. ${ }^{15}$ The Commission routinely uses "modified synchronised sampling" to select GPs for different research studies, taking into account the number of times a GP has already been sampled. ${ }^{16}$ GPs were sent an information package and an expression of interest faxback form. GPs who did not return the faxback form received a follow-up telephone call. GPs were eligible to participate if they had seen at least 600 patients aged 18-75 years in the previous year; were able to generate a computerised list of patients' details; agreed to complete a survey; and were the only GP in their practice to take part in the study.

\section{Participant selection and} screening procedures

Patient records were searched to identify all patients aged $18-75$ years who had seen the study GP in the previous year. Each GP examined the list of patients and excluded those who could not read English, were terminally ill, or resided in a nursing home.

Between January and December 2005, random samples of about 600 eligible patients from each general practice were mailed a screening survey with a covering letter from the GP. To maximise the response rate, a reminder letter was sent 2 weeks later to all patients. We collected de-identified information on the sex and age of all patients who were sent a survey.

\section{Data collection}

In the screening survey, patients were asked about demographic details, their visits to GPs and other health professionals, their "usual GP", and their overall health and 


\begin{tabular}{|c|c|}
\hline \multicolumn{2}{|c|}{1 Patient characteristics $(N=7130)$} \\
\hline Characteristic & Number $(\%)^{\star}$ \\
\hline \multicolumn{2}{|l|}{ Age (years) } \\
\hline $18-24$ & 274 (3.9\%) \\
\hline $25-34$ & 747 (10.6\%) \\
\hline $35-44$ & 1339 (19.0\%) \\
\hline $45-54$ & $1656(23.5 \%)$ \\
\hline $55-64$ & $1643(23.3 \%)$ \\
\hline $65-75$ & $1396(19.8 \%)$ \\
\hline \multicolumn{2}{|l|}{ Sex } \\
\hline Male & 2424 (34.1\%) \\
\hline Female & $4684(65.9 \%)$ \\
\hline \multicolumn{2}{|l|}{ Location of practice $^{\dagger}$} \\
\hline City (1) & 3954 (55.5\%) \\
\hline Urban (2) & 850 (11.9\%) \\
\hline Rural (3) & 195 (2.7\%) \\
\hline Rural (4) & 0 \\
\hline Remote (5) & 2131 (29.9\%) \\
\hline \multicolumn{2}{|l|}{ Patient's self-rated health } \\
\hline Excellent & 710 (10.1\%) \\
\hline Very good & 2657 (37.8\%) \\
\hline Good & $2506(35.6 \%)$ \\
\hline Fair & 970 (13.8\%) \\
\hline Poor & $196(2.8 \%)$ \\
\hline \multicolumn{2}{|c|}{ Long-term illness or disability } \\
\hline Yes & $4672(67.2 \%)$ \\
\hline No & 2277 (32.8\%) \\
\hline \multicolumn{2}{|c|}{$\begin{array}{l}\text { Length of time patient has been visiting } \\
\text { GP and/or practice }\end{array}$} \\
\hline$<1$ month & $180(2.5 \%)$ \\
\hline 1 month to $<6$ months & 310 (4.4\%) \\
\hline 6 months to $<12$ months & 335 (4.7\%) \\
\hline 12 months to $<3$ years & 1073 (15.2\%) \\
\hline 3 years to $<5$ years & $863(12.2 \%)$ \\
\hline 5 years to $<10$ years & $1278(18.1 \%)$ \\
\hline$\geqslant 10$ years & 3031 (42.9\%) \\
\hline \multicolumn{2}{|c|}{ Number of visits to GP in previous year } \\
\hline $1-2$ & $1747(24.6 \%)$ \\
\hline $3-4$ & $2257(31.8 \%)$ \\
\hline $5-6$ & 1565 (22.0\%) \\
\hline $7-11$ & 885 (12.5\%) \\
\hline$\geqslant 12$ & $647(9.1 \%)$ \\
\hline \multicolumn{2}{|c|}{ Number of GPs seen in previous year } \\
\hline 1 & 2819 (39.5\%) \\
\hline$>1$ & $4311(60.5 \%)$ \\
\hline \multicolumn{2}{|c|}{$\begin{array}{l}\mathrm{GP}=\text { general practitioner. }{ }^{*} \text { Discrepancies in totals } \\
\text { are due to missing responses. † Based on the } \\
\text { Rural, Remote and Metropolitan Areas } \\
\text { classification. }{ }^{19}\end{array}$} \\
\hline
\end{tabular}

wellbeing. The postal version of the GPAQ (Version 1.0) was also included in the survey. ${ }^{17}$ The GPAQ has six main scales (items), which relate to satisfaction with:

- receptionists (1 question);

- access to practice (11 questions);

- continuity of care (2 questions);

- communication (8 questions);

- practice nurses (3 questions); and

- the practice overall (1 question).

Patients indicated their level of satisfaction with each item, based on five-, six- or seven-point Likert scales. GPAQ item scores were expressed as a score between 0 and 100, with higher scores representing greater satisfaction. ${ }^{17}$ Patients were divided into 10year age groups to match age-group categories used by the Australian Bureau of Statistics. The youngest and oldest age groups were truncated to $\geqslant 18$ and $\leqslant 75$ years, respectively, in accordance with our eligibility criteria.

\section{Statistical analysis}

Outcome measures were the six GPAQ item scores. ${ }^{17}$ Data were summarised using means and standard deviations for continuous data (outcomes), and frequencies and percentages for categorical data (GP and participant characteristics). Our analysis excluded responses from patients who indicated that the study GP was not their usual GP. Satisfaction with nursing care was reported only for patients from practices with a practice nurse.

A mixed effects linear regression model, fitted using restricted maximum likelihood estimation and treating GP practice as a random effect, was used to calculate 95\% confidence intervals for the means and to estimate the intracluster correlation (ICC) for each GPAQ item score. When positive, the ICC can be interpreted as the proportion of the total variation in outcome due to variation between practices. The greater the variation in mean outcome between practices, the greater the ICC. ${ }^{18}$

Mixed effects linear regression models (treating GP practice as a random effect and patient characteristics as fixed effects) were also used to calculate differences in means and $95 \%$ confidence intervals for each outcome between each subgroup and the reference group for each participant characteristic, including age group, sex, geographical location, general health rating, number of visits to the patient's usual GP, and number of GPs seen in the previous year. These patient characteristics were chosen because their association with patient ratings of GP care had been previously investigated. ${ }^{12}$ It was hypothesised that a patient's level of contact with GPs (as determined by the number of visits to a GP and the number of different GPs seen in the previous 12 months) would be associated with the degree of satisfaction with GP care.

We fitted both a univariable model and a multivariable model. Only the results from the multivariable model are reported here. The $P$ values given summarise the strength of association between each outcome and patient characteristics.

All analyses were performed using Stata software, version 9.2 (StataCorp, College Station, Tex, USA)

\section{Ethics approval}

Ethics approval was granted by the University of Melbourne's Human Research Ethics Committee.

\section{RESULTS}

\section{GP response rate and demographics}

From the list of 200 GPs, 88 GPs were either ineligible, could not be contacted, or were from geographical areas in which the recruitment quota had already been reached. ${ }^{15}$ Thirty GPs (26.8\%) were recruited from the remaining 112 eligible GPs.

Of the participating GPs, three were in solo practices; of those in group practices, seven were practising with 1-3 other GPs, 10 with 4-6 other GPs, and 10 with seven or more other GPs. Eight practices did not have a practice nurse. The mean age of GPs was 52 years (SD, 9.3; range, 34-74 years); 73\% were male; $87 \%$ were Australian medical graduates; and $30 \%$ practised in rural or remote areas.

\section{Participant response rate and demographics}

From 17780 patients initially sent a screening survey, 7667 (43\%) returned a completed survey. Of these, only the 7130 patients (93\%) who reported that the study GP was their usual GP or that the practice in which the study GP practised was their usual general practice were included in our analysis.

Patient response rates by GP varied from $26.2 \%$ to $55.0 \%$. During the 12-month period (January to December 2005), there was no seasonal variation in recruitment rates (data available from authors). The average number of patients returning a completed survey per GP was 238 (range, 124- 


\section{GPAQ item scores and intracluster correlations (ICCs) for diamond study participants compared with United Kingdom national benchmarks*}

\begin{tabular}{|c|c|c|c|c|c|c|c|}
\hline \multirow[b]{2}{*}{ Satisfaction with: } & \multicolumn{5}{|c|}{ diamond study participants $(N=7130)$} & \multicolumn{2}{|c|}{ UK national benchmarks ${ }^{\dagger}(N=20146)$} \\
\hline & $n$ & Mean item score $\left(95 \% \mathrm{Cl}^{\ddagger}\right)$ & SD & $\begin{array}{l}\text { Range in mean scores } \\
\text { between practices }\end{array}$ & $I C C^{\ddagger}$ & $n$ & Mean item score $(95 \% \mathrm{Cl})$ \\
\hline Receptionists & 7122 & $81.8(79.6-83.5)$ & 18.9 & $69.0-90.4$ & 0.080 & 19803 & $69.1(68.8-69.5)$ \\
\hline Access to practice & 7111 & $68.6(66.1-71.0)$ & 16.7 & $57.2-84.1$ & 0.163 & 19302 & $58.3(58.0-58.6)$ \\
\hline Continuity of care & 7080 & $76.5(74.0-78.7)$ & 20.5 & $65.3-89.3$ & 0.098 & 18586 & $66.1(65.7-66.4)$ \\
\hline Communication & 7104 & $84.0(82.2-85.4)$ & 15.9 & $75.4-94.0$ & 0.077 & 18528 & $75.9(75.6-76.2)$ \\
\hline Nursing care c $^{\S}$ & 2142 & $80.0(77.0-81.4)$ & 16.6 & $66.7-89.3$ & 0.082 & 13740 & $76.3(76.0-76.6)$ \\
\hline Practice overall & 7097 & $81.6(80.4-82.5)$ & 20.4 & $75.4-94.0$ & 0.016 & 19039 & $76.5(76.2-76.8)$ \\
\hline
\end{tabular}

316 patients per GP). Participant characteristics are summarised in Box 1. Compared with the total sample of patients who were sent the screening survey, the mean age of respondents was slightly higher (51 years [SD, 14.1 years] v 46 years [SD, 15.3 years]), and the proportion of respondents who were women was slightly higher $(65.9 \%$ v $60.7 \%)$.

\section{General practice assessment questionnaire}

The proportion of missing responses was less than 3\% for each GPAQ item. Responses to all items were well distributed across response categories. Summary measures and the ICC for each GPAQ item, together with postal benchmarks from the UK GP contract year April 2004 to March $2005^{20}$ are presented in Box 2. Mean scores for the six GPAQ items ranged from 68.6 (95\% CI, 66.1-71.0) for satisfaction with access to 84.0 (95\% CI, 82.2-85.4) for satisfaction with communication, and were higher than the UK benchmarks.

The majority of participants $(77.0 \%$ [5483/7122]) rated treatment by receptionists as "excellent" or "very good"; 56.3\% (4000/7107) of patients reported usual waiting times at the clinic to be 11-30 minutes, and a further $17.9 \%$ (1270/7107) reported usual waiting times of over 30 minutes. Of patients who reported usual waiting times of $\geqslant 11$ minutes, $65.4 \%$ (3432/5250) rated their satisfaction with usual waiting times as "very poor", "poor" or "fair", compared with only $7.9 \%(144 / 1824)$ of patients who waited less than 11 minutes.

Results of the multivariable regression analysis for each of the six GPAQ items, categorised by selected participant characteristics, are presented in Box 3. The differences presented have been adjusted for the effect of the remaining participant characteristics listed in the table. The results for each outcome are interpreted as the adjusted difference in mean score between the categories of each participant characteristic and the chosen reference category. For example, the adjusted difference in mean score for satisfaction with receptionists between the oldest age group and youngest age group in the sample (the reference group) is 6.6, and we can be $95 \%$ confident that the true difference in the mean score for the two age groups in the population lies between 4.2 and 9.0 - indicating that, on average, the oldest patients rated satisfaction with receptionists higher than did the youngest patients.

Older patients, particularly those over 65 years, gave higher ratings than younger patients on each of the GPAQ scales. Female patients gave slightly higher ratings than male patients on satisfaction with receptionists, communication, nursing care and the practice overall. Patients residing in remote areas reported a greater level of satisfaction with nursing care than patients in city areas. Self-rating of health as excellent or very good and higher frequency of general practice visits over the previous 12 months were strongly associated with greater satisfaction with GP care. Compared with patients who had seen only one GP in the previous year, patients who had seen more than one GP were less satisfied with each aspect of care (except nursing care), with the greatest level of dissatisfaction being reported in relation to continuity of care.

\section{DISCUSSION}

To our knowledge, ours is the first study to examine patient perceptions of the quality of health care in general practice using the GPAQ scale on a large sample of Australian patients. Administering a postal survey enabled us to sample a large, geographically diverse group of patients at relatively low cost. Our approach provides patient-reported quality ratings that can be attributed to individual doctors and practices. The minimal missing data in completed questionnaires suggests that the GPAQ is suitable for use in Australia. Unlike most epidemiological studies administering postal questionnaires, we were able to report information on age and sex of the entire patient sample sent a survey.

Several factors should be taken into account when considering the generalisability of our results. Firstly, the GPAQ was one of several questionnaires embedded within a survey about mental health. This may have influenced the response rate as well as the type of patients who chose to complete and return a questionnaire. Secondly, eligibility criteria for GPs and patients may have influenced the selection of participants: $11.2 \%$ of Australian general practices are not fully computerised, ${ }^{21}$ which may affect patients' perceptions of access; and excluding GPs who see fewer than 600 patients a year may have biased the sample towards GPs working full-time (predominantly men). ${ }^{22}$ Thirdly, as the sample was limited to patients who had consulted their GP in the previous year, the views of patients consulting their GP less frequently may have been under-represented. 


\section{Results of multivariable linear regression analysis for each GPAQ item score, by patient characteristic*}

GPAQ item

\begin{tabular}{|c|c|c|c|c|c|c|}
\hline & $\begin{array}{l}\text { Receptionists } \\
(N=6935)\end{array}$ & $\begin{array}{l}\text { Access to practice } \\
(N=6924)\end{array}$ & $\begin{array}{l}\text { Continuity of care } \\
\qquad(N=6895)\end{array}$ & $\begin{array}{c}\text { Communication } \\
(N=6918)\end{array}$ & $\begin{array}{l}\text { Nursing care } \\
(N=2085)^{\dagger}\end{array}$ & $\begin{array}{l}\text { Overall satisfaction } \\
(N=6914)\end{array}$ \\
\hline Patient characteristic & Diff $(95 \% \mathrm{Cl})$ & Diff $(95 \% \mathrm{Cl})$ & Diff $(95 \% \mathrm{Cl})$ & Diff $(95 \% \mathrm{Cl})$ & Diff $(95 \% \mathrm{Cl})$ & Diff $(95 \% \mathrm{Cl})$ \\
\hline Age (years) & $P<0.001$ & $P<0.001$ & $P<0.001$ & $P=0.014$ & $P<0.001$ & $P<0.001$ \\
\hline $18-24$ & Ref & Ref & Ref & Ref & Ref & Ref \\
\hline $25-34$ & $-0.5(-3.0,2.0)$ & $-2.6(-4.6,-0.5)$ & $1.1(-1.5,3.8)$ & $0.3(-1.8,2.4)$ & $0.4(-3.7,4.4)$ & $0.2(-2.6,3.0)$ \\
\hline $35-44$ & $1.4(-1.0,3.7)$ & $-2.1(-4.0,-0.1)$ & $1.7(-0.8,4.2)$ & $2.2(0.3,4.2)$ & $4.4(0.6,8.2)$ & $0.2(-2.5,2.8)$ \\
\hline $45-54$ & $3.6(1.3,5.9)$ & $-0.6(-2.5,1.3)$ & $3.2(0.7,5.6)$ & $1.7(-0.2,3.7)$ & $3.5(-0.2,7.2)$ & $-0.3(-2.9,2.3)$ \\
\hline $55-64$ & $4.4(2.0,6.7)$ & $1.4(-0.6,3.3)$ & $6.2(3.8,8.7)$ & $2.4(0.4,4.3)$ & $3.4(-0.3,7.2)$ & $1.8(-0.8,4.4)$ \\
\hline $65-75$ & $6.6(4.2,9.0)$ & $4.1(2.1,6.1)$ & $6.3(3.8,8.9)$ & $1.7(-0.3,3.7)$ & $5.8(2.1,9.5)$ & $3.0(0.4,5.7)$ \\
\hline Sex & $P<0.001$ & $P=0.074$ & $P=0.17$ & $P<0.001$ & $P<0.001$ & $P=0.032$ \\
\hline Male & Ref & Ref & Ref & Ref & Ref & Ref \\
\hline Female & $2.0(1.0,2.9)$ & $0.7(-0.1,1.5)$ & $0.7(-0.3,1.7)$ & $1.8(1.0,2.6)$ & $3.3(1.8,4.8)$ & $1.2(0.1,2.2)$ \\
\hline Practice attended ${ }^{\ddagger}$ & $P=0.29$ & $P=0.43$ & $P=0.60$ & $P=0.28$ & $P<0.001$ & $P=0.86$ \\
\hline City (1) & Ref & Ref & Ref & Ref & Ref & Ref \\
\hline Urban (2) & $-0.4(-6.8,6.0)$ & $-3.7(-11.6,4.2)$ & $-2.9(-9.6,3.7)$ & $1.0(-4.4,6.3)$ & $1.7(-4.3,7.6)$ & $-0.7(-4.1,2.7)$ \\
\hline Rural (3) & $1.7(-8.9,12.3)$ & $6.9(-6.2,20.0)$ & $3.7(-7.3,14.8)$ & $-5.5(-14.4,3.3)$ & $6.4(-1.3,14.2)$ & $-1.3(-7.2,4.5)$ \\
\hline Remote (5) & $4.2(-0.2,8.5)$ & $2.0(-3.4,7.4)$ & $-1.9(-6.5,2.6)$ & $-2.7(-6.4,0.9)$ & $7.4(3.9,11.0)$ & $0.6(-1.8,2.9)$ \\
\hline Patient's self-rated health & $P<0.001$ & $P<0.001$ & $P<0.001$ & $P<0.001$ & $P<0.001$ & $P<0.001$ \\
\hline Excellent & Ref & Ref & Ref & Ref & Ref & Ref \\
\hline Very good & $-2.0(-3.5,-0.5)$ & $-3.1(-4.4,-1.8)$ & $-4.3(-5.9,-2.7)$ & $-3.7(-5.0,-2.5)$ & $-5.6(-8.2,-3.0)$ & $-3.2(-4.9,-1.5)$ \\
\hline Good & $-5.6(-7.2,-4.1)$ & $-6.4(-7.7,-5.1)$ & $-7.9(-9.5,-6.2)$ & $-7.4(-8.7,-6.1)$ & $-8.8(-11.4,-6.1)$ & $-4.8(-6.6,-3.1)$ \\
\hline Fair & $-6.6(-8.4,-4.7)$ & $-8.7(-10.3,-7.1)$ & $-10.5(-12.5,-8.5)$ & $-10.4(-11.9,-8.8)$ & $-10.0(-13.0,-6.9)$ & $-6.7(-8.8,-4.6)$ \\
\hline Poor & $-5.5(-8.4,-2.5)$ & $-10.4(-12.8,-7.9)$ & $-11.0(-14.1,-7.9)$ & $-10.1(-12.6,-7.6)$ & $-14.2(-18.6,-9.8)$ & $-7.0(-10.3,-3.7)$ \\
\hline $\begin{array}{l}\text { Visits to GP in previous } \\
12 \text { months }\end{array}$ & $P<0.001$ & $P<0.001$ & $P<0.001$ & $P<0.001$ & $P<0.001$ & $P<0.001$ \\
\hline $1-2$ & Ref & Ref & Ref & Ref & Ref & Ref \\
\hline $3-4$ & $1.9(0.8,3.1)$ & $1.3(0.3,2.3)$ & $2.2(0.9,3.4)$ & $2.9(1.9,3.8)$ & $-0.8(-2.9,1.1)$ & $0.6(-0.7,1.9)$ \\
\hline $5-6$ & $4.6(3.3,5.9)$ & $2.6(1.5,3.7)$ & $4.6(3.2,6.0)$ & $4.4(3.3,5.5)$ & $2.1(-0.1,4.3)$ & $2.4(0.9,3.8)$ \\
\hline $7-11$ & $6.7(5.1,8.3)$ & $4.4(3.1,5.8)$ & $5.6(4.0,7.3)$ & $6.0(4.6,7.3)$ & $2.1(-0.4,4.6)$ & $2.6(0.8,4.4)$ \\
\hline$\geqslant 12$ & $8.8(7.0,10.6)$ & $7.4(5.9,8.9)$ & $9.1(7.2,11.0)$ & $8.2(6.7,9.7)$ & $8.1(5.4,11.0)$ & $5.9(3.9,7.9)$ \\
\hline $\begin{array}{l}\text { Number of GPs seen in } \\
\text { previous } 12 \text { months }\end{array}$ & $P=0.003$ & $P<0.001$ & $P<0.001$ & $P<0.001$ & $P=0.93$ & $P<0.001$ \\
\hline 1 & Ref & Ref & Ref & Ref & Ref & Ref \\
\hline$>1$ & $-1.5(-2.4,-0.5)$ & $-2.1(-2.9,-1.4)$ & $-8.4(-9.4,-7.4)$ & $-3.1(-3.9,-2.3)$ & $-0.4(-1.6,1.6)$ & $-2.3(-3.3,-1.2)$ \\
\hline
\end{tabular}

Other factors may have influenced the responses to our survey. Patients satisfied with their care may be more likely to complete satisfaction surveys. While response rates to surveys filled out in the doctor's waiting room are usually higher than response rates to postal surveys, ${ }^{23}$ completing postal surveys in the privacy of one's home may encourage more careful consideration of responses and result in fewer missing answers. ${ }^{23,24}$ Similarly, when measuring satisfaction, some patients may be reluctant to report negative experiences if they perceive that their responses may be accessed by the GP or practice staff. Bower et al identified bias towards a higher GPAQ score (ie, more favourable rating) among waiting room responders compared with postal responders. ${ }^{14}$ While this bias was greatest with regard to the receptionist item, GPAQ scores were higher across all items in the waiting room version. This is consistent with other studies of quality measures in primary care that have compared postal and waiting room surveys. ${ }^{23,25}$ In our study, the anonymity of the postal survey may have provided a welcome opportunity for patients who were dissatisfied with their care to express their views confidentially. 
Overall, participants rated general practice care highly on the six GPAQ items, and GPAQ scores for each item were higher in our study than UK national benchmarks. ${ }^{20}$ Higher scores in our sample may be partially attributable to differences in the organisation of general practice: while Australians are free to consult any GP for their own health care, UK patients who consult GPs under the National Health Service are allocated to a GP based on postcode of residence and catchment area of the general practice. However, the observed differences in GPAQ scores between the two countries are likely to be mainly the result of the sampling methods used: the GPs who took part in our study were those who agreed to participate in mental health research, which may have led to the recruitment of a higher calibre of GP than one might expect from a compulsory quality assurance program.

Our finding that older patients gave higher ratings than younger patients on most of the GPAQ scales is consistent with the results of a UK study by Campbell et al. ${ }^{12}$ However, in contrast with that study, we found that female patients gave slightly higher ratings than male patients on satisfaction with receptionists, communication, nursing care and the practice overall. The strongest patient factors predicting higher GPAQ scores were self-rating of health as excellent or very good and frequency of general practice visits.

The association between GPAQ scores and patient characteristics may reflect the actual quality of care patients receive, but may also be partially explained by different patient expectations of GP care, overall engagement with general practice, and/or variation in reporting between patient groups. ${ }^{12}$

GPAQ scores are useful, as they enable comparisons of general practice care across time, between practices and between patient subgroups. At this time, it is difficult to interpret the clinical significance of our results, as the GPAQ is relatively new and we lack comparative Australian data. ${ }^{26}$ Increased use of the GPAQ will facilitate a greater understanding of the clinical meaning of the GPAQ scores.

\section{ACKNOWLEDGEMENTS}

The diamond study was funded by the National Health and Medical Research Council and the Victorian Centre of Excellence in Depression and Related Disorders, an initiative between beyondblue and the Victorian Government. Neither funding body had a role in the study design; the collection, analysis and interpretation of data; the writing of the manuscript; or the decision to submit the manuscript for publication. We acknowledge the 30 dedicated GPs, their patients and practice staff for making our research possible. We thank the diamond project team, including the associate investigators and researchers involved in the study: Ms Darshini Ayton, Ms Vanessa Madden, Dr David Pierce, Dr Lena Sanci, Dr Jane Sims, Ms Donna Southern and the casual research staff. We also thank Felicity Goodyear-Smith for her feedback on an early draft of our article.

\section{COMPETING INTERESTS}

None identified.

\section{AUTHOR DETAILS}

Maria Potiriadis, GradDipClinEpi, BAppSc, Senior Research Assistant ${ }^{1}$

Patty Chondros, MSc(Stats),

GradDipEpiBiostats, BSc(Hons), Lecturer ${ }^{1}$

Gail Gilchrist, PhD, GradDipAlcDrugStud,

BA(Hons), Senior Research Fellow ${ }^{2}$

Kelsey Hegarty, MB BS, FRACGP, PhD,

Associate Professor ${ }^{1}$

Grant Blashki, MB BS, FRACGP, Research

Fellow ${ }^{1}$

Jane M Gunn, MB BS, FRACGP, PhD, Professor and Research Director ${ }^{1}$

1 Primary Care Research Unit, Department of

General Practice, University of Melbourne,

Melbourne, VIC.

2 Substance-Related Disorder Research Group,

Institut Municipal d'Investigació Mèdica

(IMIM)-Hospital del Mar, Barcelona, Spain.

\section{Correspondence:}

m.potiriadis@unimelb.edu.au

\section{REFERENCES}

1 Wensing $\mathrm{M}$, Grol R, Smits A. Quality judgements by patients on general practice care: a literature analysis. Soc Sci Med 1994; 38: 45-53.

2 Davies AR, Ware JE Jr. Involving consumers in quality of care assessment. Health Aff (Millwood) 1988; 7: 33-48

3 Donabedian A. Quality assurance in health care: consumers' role. Qual Health Care 1992; 1: 247251.

4 Donabedian A. The quality of care: how can it be assessed? JAMA 1988; 12: 1743-1748.

5 Howie JG, Heaney DJ, Maxwell M, Walker JJ. A comparison of a Patient Enablement Instrument (PEI) against two established satisfaction scales as an outcome measure of primary care consultations. Fam Pract 1998; 15: 165-171.

6 Baker R. Development of a questionnaire to assess patients' satisfaction with consultations in general practice. Br J Gen Pract 1990; 40: 487490.

7 Poulton BC. Use of the consultation satisfaction questionnaire to examine patients' satisfaction with general practitioners and community nurses: reliability, replicability and discriminant validity. Br J Gen Pract 1996; 46: 26-31.

8 Wolf MH, Putnam SM, James SA, Stiles WB. The Medical Interview Satisfaction Scale: development of a scale to measure patient perceptions of physician behavior. J Behav Med 1978; 1: 391-401.

9 Bower P, Roland M, Campbell J, Mead N. Setting standards based on patients' views on access and continuity: secondary analysis of data from the general practice assessment survey. BMJ 2003; 326: 258.

10 Donovan JL. Patient decision making. Int J Technol Assess Health Care 1995; 11: 443-455.

11 Ramsay J, Campbell JL, Schroter S, et al. The General Practice Assessment Survey (GPAS): tests of data quality and measurement properties. Fam Pract 2000; 17: 372-379.

12 Campbell J, Ramsay J, Green J. Age, gender, socioeconomic, and ethnic differences in patients' assessments of primary health care. Qual Health Care 2001; 10: 90-95.

13 Bower P, Mead N, Roland M. What dimensions underlie patient responses to the General Practice Assessment Survey? A factor analytic study. Fam Pract 2002; 19: 489-495.

14 Bower P, Roland MO. Bias in patient assessments of general practice: general practice assessment survey scores in surgery and postal responders. Br J Gen Pract 2003; 53: 126-128.

15 Gunn JM, Gilchrist GP, Chondros P, et al. Who is identified when screening for depression is undertaken in general practice? Baseline findings from the Diagnosis, Management and Outcomes of Depression in Primary Care (diamond) longitudinal study. Med J Aust 2008; 188 (12 Suppl): S119-S125.

16 Calcino G. Sampling from the HIC data set. Proceedings of the General Practice Evaluation Program 1993 work-in-progress conference; 1993 May 20-22; Canberra, Australia. Canberra: Department of Health, Housing, Local Government and Community Services, 1993.

17 Roland M. General practice assessment survey (GPAS-2) manual. Manchester: National Primary Care Research and Development Centre, University of Manchester, 2002.

18 Adams G, Gulliford MC, Ukoumunne OC, et al. Patterns of intra-cluster correlation from primary care research to inform study design and analysis. J Clin Epidemiol 2004; 57: 785-794.

19 Australian Institute of Health and Welfare. Rural, regional and remote health: a guide to remoteness classifications. Canberra: AlHW, 2004. (AlHW Cat. No. PHE 53.) http://www.aihw.gov.au/publications/index.cfm/title/9993 (accessed Jun 2008).

20 National Primary Care Research and Development Centre, UK. GPAO - a patient questionnaire for the GP contract. http://www.gpaq.info/ index.htm (accessed Jun 2008).

21 Henderson J, Britt H, Miller G. Extent and utilisation of computerisation in Australian general practice. Med J Aust 2006; 185: 84-87.

22 Australian Government Department of Health and Ageing. General practice in Australia 2004. Canberra: DoHA, 2005.

23 Gribble RK, Haupt C. Quantitative and qualitative differences between handout and mailed patient satisfaction surveys. Med Care 2005; 43: 276-280.

24 Cartwright A. Who responds to postal questionnaires? J Epidemiol Community Health 1986; 40: 267-273.

25 Kinnersley P, Stott N, Peters T, et al. A comparison of methods for measuring patient satisfaction with consultations in primary care. Fam Pract 1996; 13: 41-51.

26 Mead N, Bower P, Roland M. The General Practice Assessment Questionnaire (GPAQ) — development and psychometric characteristics. BMC Fam Pract 2008; 9: 13.

(Received 5 Feb 2008, accepted 10 Jun 2008) 